\title{
Seeing Real Life?
}

Working With the Visual to Understand Landscapes of Community Andrew Clark

\begin{abstract}
This paper reports on the use of visual techniques and data as part of a multimethod investigation exploring the temporal and spatial contexts of social connections and community formation in an economically and socially heterogeneous inner city neighbourhood. The paper provides a reflective commentary on the use of two visually orientated methods (participatory mapping and walking interviews) and explores how working with the visual offers particular analytical insight. Discussion moves beyond existing debates about the benefits of using visual methods to argue that understanding how visual methodologies illuminate social phenomena needs to take account of the participative and performative processes that underpin them.
\end{abstract}

Keywords: visual methods, participatory mapping, walking interviews, reflexivity, community, neighbourhoods 


\section{Introduction}

In this paper I consider the nature of the knowledge produced through visually focused techniques developed as part of a mixed-method study investigating the dynamics of social networks and community interactions through a multidimensional neighbourhood case study. The research explored how different sociodemographic groups constructed networks of friends, relatives, neighbours, and service providers and how these networks are maintained over time and across space. The discussion presented here focuses on two methods deployed in the research: participatory social mapping and mobile interviews. Increasingly these techniques are being used to investigate socially and spatially situated relations. Their use is often associated with a number of claims about how visual material and visual methodologies more generally are better tools for grasping the nuances and complexities of life than 'more conventional' (text and number-based) methods.

While I do not take issue with the potential power of the visual to add to our understanding of the social world, there is a need to more fully assess the extent to which expectations for deploying visual methods are met (Pain, 2012). In doing so, I offer a reflexive appraisal of the nature of visual research and the types of understanding they give rise to. I consider how the visual worked alongside other modalities of knowledge and reflect on how some of the (visually orientated) data can produce seemingly competing or contradictory interpretations of reality. Consequently, I suggest that the visual methods do not just represent the world differently to word- and number-based techniques, they also come to construct it through their performative nature.

For some time, visual methodologies have been heralded as part of an innovative turn in social science methodologies. Yet alongside this celebrative rhetoric is a growing scepticism 
about the innovativeness of methodological claims (Wiles, Bengry-Howell, Crow, \& Nind, 2013). For instance, Sweetman (2009) has raised concerns about what he calls a fetishization of (visual) method, with visual researchers paying more attention to their preferred 'way of looking' (p. 492) rather than what they might be looking at. Cautious of claims for the potential innovativeness of the methods I describe below, there is nonetheless much to be said for the development of a more 'seeing' visual methodology (Prosser, 2011). Inferentially, visual methods seem to be somehow better able to access the full range of sensorial, experiential, and phenomenological dimensions of social life (Back, 2007; Pink, 2012). For instance, Pain (2012) has outlined three reasons researchers claim to use visual methods: to enhance data collection or presentation, for example by building rapport or facilitating communication through the provision of prompts; to facilitate the expression of subconscious and tacit knowledge; and to mediate the relationship between a researcher and a participant, drawing predominantly on participatory research paradigms. Felstead, Jewson, and Walters's (2004) comments on the benefits of adopting visual methodologies summarize much of the discussion:

Making and analyzing images not only generates substantive findings but also create[s] new leads in the research process and sensitise[s] us to our own unquestioned assumptions. The process was invaluable in itself, independently of its outcome. The photographs contained more information ... than ever could have been captured by interview. Words could not have represented the wealth of data contained in the photographs. (as cited in Holm, 2008, p. 339)

These are persuasive, if perhaps rather bold, claims. Given arguments about the subjective nature of knowledge, the need for reflexive engagement of its production, and questions about what different approaches can bring to our understanding of social phenomena, it is important to consider how this knowledge comes into being and how we might assess it relative to other knowledge clams. Yet the 'recognition that all scientific knowledge is 
“provisional", "positioned" and incomplete' (Pauwels, 2012, p. 260) raises important questions about the value of working with the visual to understand the social world. What, if anything, does the visual add to our understanding of phenomena? Does this understanding differ from that which might be obtained through other forms of written, spoken, or numerical representations? How can researchers critically engage in reflexive assessment of visual materials and the ways they are produced without succumbing to overtly $\mathrm{r}$ elativist or deeply personal or autobiographical accounts of the research process that may mask or divert from substantive analysis and reporting? And how do visual methods work with, or against, other methods of data collection? Ultimately, my intention here is to contribute to attempts to unravel what, if anything, researching with the visual can tell us about the world.

\section{Study Context: Researching Networks, Neighbourhoods, and Community}

My reflections come from a qualitatively driven multimethod investigation of networks, neighbourhoods, and communities. This aimed to understand how people perceive of and maintain social relations in different contexts, with an emphasis on understanding the ways in which these relationships intersect with and transcend (locally situated) neighbourhood ties. The research investigated the networks, interactions, and relationships within and across place by deploying a mix of methods to understand the communicative and embodied practices that make up an individual's networks of contacts (including friends, relatives, and acquaintances) and how these operate across social, spatial, and 'real' and 'virtual' domains.

Further discussion of the methodological approach is available elsewhere (Emmel \& Clark, 2009). A single neighbourhood as a case study in an inner city district of a large northern U.K. city formed the geographical context for the work, though no predetermined boundaries 
ANDREW CLARK

were imposed on the neighbourhood in question. Within a heterogeneous resident population, we explored how different social, economic, and cultural groups, seemingly living in the same geographic space, formed and maintained connections with others locally and across a wider geographical sphere and made sense of the locations they shared. The research made use of a number of conventional ethnographic methods, including participant observation; interviews with key informants such as long-term residents, community stakeholders, and voluntary sector workers; and historical and quantitative data collection. Importantly, a core group of 24 individuals, aged 18 to 30 from a variety of social, cultural, and economic backgrounds, was recruited to complete a range of methods, including participatory social maps and walking interviews. Both methods formed the basis of discussion here and contained a strong visual component.

Reasons for developing data collection techniques that emphasized the visual included the belief that not everything in life can be expressed verbally or through text and that visual techniques could help reveal those less-often-articulated dimensions of social life. Conscious of critiques of more conventional methods from participatory research, we were aware that some verbal and text-based methods may be potentially exclusionary or alien to some participants. We also aspired to encourage participants to think about their communities in ways that were meaningful to them, rather than through researcher-imposed questioning techniques such as semistructured interviews or questionnaires. Driving our methodological choices then was a belief that the data collected might more closely resemble the realities that they purport to represent. 


\section{Working With the Visual: Reflecting on Two Techniques}

\section{Method 1: Participatory Network Maps}

Participatory mapping has been used in two main ways: either to garner rapid knowledge about a locality or to understand knowledge about a particular issue that can be explored through further elicitation (Heath, Fuller, \& Johnston, 2009). Here, the method was developed to metaphorically explore the social landscape of participants' networks and to encourage participants to articulate and represent their social networks, including how they perceive, create, and maintain their networks over time and in different contexts. The technique began with a core guiding request of all participants: Tell me about the people who you know. We then proceeded to address additional themes of making and losing contacts; the geography, temporality, and familiarity of contacts; and how contacts are mediated in different contexts. Participants were provided with paper, pens, and sticky notes with which to draw out the contacts, and the interaction was audio and visually recorded. Most took about 60 to 90 minutes to complete the task, though two requested to keep their network map to complete and return them to us. Discussions focused upon the nature and type of relations developed during the mapping, though they also focused on the research aims of interrogating the nature and meaning of ties and contacts and soliciting reasons for why the map was produced in the way it was.

The method encouraged, and arguably enabled, participants to not only list and describe but also categorize their relationships with others through grouping, associating, and disassociating members of the networks being constructed and describe, visually as well as orally, how different relationships make up social domains and are maintained in different contexts. At the most obvious level, the maps then provide a visible guide that can be used to structure the discussion, highlighting if not what, then at least who, to talk about. They also act 
ANDREW CLARK

as elicitation devices to encourage participants to recollect other important and not-so-important others. Finally, the relative positioning of individuals on the network map enables the separation and categorization of individuals into domains without necessarily forcing separate distinctions between them.

However, analysis of the maps as standalone visual representations (as kinds of sociograms for social network analysis) is impossible. For instance, the names detailed on the maps have little meaning in and of themselves, nor do they offer any indication of why they are there or the relationship between each other and the participant. Nor is it possible to understand how they came to be included on the map or their contextual significance in 'real life'. While others have suggested that it ought to be possible to produce a composite network for the research location, taking such cues from social network analysis is neither possible nor methodologically appropriate. Informed by what Knoke and Yang (2008) refer to as realist strategies for determining network boundaries (see also Heath et al., 2009), we did not ask participants to list everybody, or even the most important people, they knew. Instead, we were interested in how relationships were experienced (or at least articulated) and understood. In addition, because participants were instructed to represent their networks in whatever ways they thought most appropriate, each network map was structurally unique in so far as it depicted the structural components of a network. Some participants were keen to attempt to complete 'full' network maps, requesting at the end of the interview to take away the unfinished piece, while for the majority of participants, production and discussion of their networks stopped at the end of the interview. Rather than accurate depictions of individual networks, the network maps offer visual indications of how networks are interpreted and experienced. 


\section{[Insert Fig01 here]}

Figure 1. Visualizing a complete network

Illustrating these points, Rachel's ${ }^{1}$ network map (Figure 1) represents her attempt to provide as complete a network as possible (Emmel, 2008). While this is a somewhat impossible task, it is nonetheless indicative of how she came to view this exercise. Rachel talked about how important it was for her to put down all the names, as though the network map offered a complete representation of everyone she knew. In developing the map, Rachel used a variety of pen types, colours, and coding categories to help her explain the meaning of the relationships she had. So, in Figure 1, different colours and pen styles represent different domains in her life, different relationship types, and a sense of relative closeness (those names completed in finer-ink compared with the thicker text represent those less emotionally close to her). The links and lines between the domains helped Rachel articulate what we came to understand as bridging and bonding ties between different parts of her networked life. Finally, towards the end of the exercise, some names were circled, again in specific colours to indicate, in Rachel's view, those individuals whom she felt supported her most in times of need. Here, Rachel was quite explicit about the importance of these circles, commenting on how she felt she spent much of her time caring for others while commenting on the limited nature of this reciprocity and on how few people she felt she could really turn to support her in return.

\section{[Insert Fig02 here]}


ANDREW CLARK

Figure 2. Locally dense networks with less well-connected nodes (some names anonymized)

A second map, created by Daniel (Figure 2), indicates a rather different approach. Daniel's map demonstrates two distinct themes in the ways in which he reflected on his social networks. He depicts a large number of locally situated, socially dense friends and acquaintances, exemplified by relatively extensive network in the centre of his map. He also has some contacts (in this case family and a close friend) who are not so well interconnected with the rest of his network. What we observe, then, is the inherent localness of his network, but at the same time there is reference to friends and family in other parts of the country, including the 'islands' or domains at the bottom of the network map indicating grandparents, his mother and her new partner, and a 'best friend' who had moved to a different part of the United Kingdom. In producing the map, Daniel articulated visually, if not verbally, the social distance imposed by the relocation of some of his friends and family to a different part of the country, where they become disconnected (evident through the absence of any visible network ties) to the rest of Daniel's much more local network. In doing so, he raises an important question about how participants translate methods into practice, in Daniel's case about how the phrase map is interpreted as a cartographic representation but also about how the maps work as visual depictions of complex social practices, connections, and emotions. There is a strong visual sense of a localized set of social relations, inferring an ongoing need to recognize the importance of local, and locality-based, social ties regardless of the persuasiveness of globalization discourses. In addition, the technique produces visual clues about the relative positioning of individuals within a wider network. Ultimately though, Daniel's attempt at providing geographical causality for his networks fails because it is too difficult for him to satisfactorily represent his socially 
constituted network spatially. Nonetheless, in attempting to do so, Daniel is able to tell his own story about the location-specific nature of his relationships with others.

Reflecting on the network maps I am conscious of Amsden and Van Wynsberghe's (2005) observation that the network maps 'offer a rich and layered description of the mapmakers' perspective of the local environment. ... [They] are therefore able to capture emotional and other abstract connections experienced by the mapmaker' (p. 361). I think some of this emotional connection, and disconnection, can be seen in both Rachel's and Daniel's maps. For instance, Rachel tries to include as many names as possible for worry of omitting someone important while Daniel demonstrates a potential rupture in his relationship with family and friends he is no longer (geographically) close to. Daniel struggled to articulate the distance that had developed, but his visual depiction offers a way to represent this as best he could.

However, the maps go beyond visual depicters of ties and relationships. Their production hints at a shift from description to one of categorization and, importantly, explanation. To return to Rachel's map, she was able to not just describe how different individuals were categorized, but she also provided an explanation for those relationships. So, the method offers participants greater control of how they wanted to represent their social networks, albeit within the constraints of our desire to 'map out' the data in some way. Participants could determine which contacts were meaningful to them and reflected on why those contacts were meaningful. Nor were participants restricted to the type or nature of their contacts, and they frequently made reference to friends, neighbours, work colleagues, family members, and individuals from the past. In covering a variety of types of contact, participants were able to consider their community as a more holistic unit while still situating these contacts in particular contexts and lived experiences. 
ANDREW CLARK

To be clear, the research did not, explicitly, intend to achieve the emancipatory goals of most participatory research. Nonetheless, and as Cook (2012) proposes, participatory research can potentially have an impact on participants by shaping their thoughts, knowledge, and practices as well as on researchers by affecting the theories they draw from the research for practice. By providing an analytical rather than simply descriptive account of their network maps, participants were better able to contribute to the authenticity and credence of our accounts of their lives, and therefore contributed, albeit in a relatively small way, to a wider process of knowledge creation. So, as a visual process of co-creation, the maps became crucial in helping participants structure, assess, and explain their thoughts. Participants also made comparisons across and within categories, comparing, for example, the different types of relationships with different friends and the circumstances when different contacts were considered more or less significant. In this way, the maps are not just data to be analysed later but devices that reveal the fluid, multidimensional nature of contacts, as articulated and analysed in-situ by their participantcreators (Emmel, 2008). And while participants may not engage in a 'pure' form of participative research, their role as knowing subjects of their own social worlds (Bergold \& Thomas, 2012) comes to the fore in their articulation of why they chose to represent their networks in the way they did.

\section{Method 2: Walking Interviews}

Walking interviews are part of what has been described as a mobile turn in the social sciences (Fink, 2012; Hogan, 2011). Here, they were developed to provide insight into how contacts and ties are embedded in and receptive to place and to produce data on how perceptions of neighbourhood spaces might inform senses of community. The interviews began with a common 
open request of all participants to 'show me around your neighbourhood'. What was meant by neighbourhood was left open to interpretation, and no restrictions were placed on the size of the neighbourhood or the length of time available for the walk. Participants were given prior notice to allow time to plan where to take us and were provided with a disposable camera with which to photograph 'anything' they wanted. As a consequence, we again drew on the perceived benefits of placing participants in greater control of interpreting, applying, and adapting our intended approach to data collection. As the walk progressed, questions were asked about where we were walking, why we had been brought to a particular spot, and what the location and route meant to the participant. Further questions probed for the type and extent (if any) of the participants' social networks in the area. The walks varied in length from 20 minutes to more than five hours, taking in shops, places of worship, bars and cafes, houses where participants had previously lived, and the homes of friends, neighbours, and family, sometimes including prearranged 'dropins' to witness neighbourly practices 'in action'. Three participants requested that we conduct all, or part, of the interview by car.

The interviews afforded participants the opportunity to offer their interpretations of what neighbourhood meant and where it is located. Giving participants freedom to choose their own locations to show us and routes to travel along meant we went on many different kinds of walks. Some walks were structured around events significant to participant biographies, others around localized contacts such as friends or family living nearby. Participants provided insight into the spatial contexts of everyday life and, importantly, came to appreciate the significance of neighbourhood spaces as the location for specific ties. In many walks, we met acquaintances on the street, and, as noted, several had arranged for us to call in on friends and relatives in the area. 
ANDREW CLARK

The neighbourhoods we walked through were not bounded or fixed locations in which community ties somehow just happened; rather spaces within and beyond the neighbourhood were instrumental in enabling these ties to develop. I learnt where participants did and did not go and about how the neighbourhood has changed relative to participants' changing lives. The walks also revealed some of the ways in which time, biography, and memory shape understandings of the neighbourhood as a social space. In doing so, I gained an understanding of the temporality of community lives, hearing the shared stories and seeing the shared spaces that together produce collective memories of neighbourhood life that are played out in everyday practices. Moreover, it became possible to understand how the neighbourhood was the product of relational understandings of other spaces and how life within it was constructed in relation to events that happened elsewhere, such as friends' and relatives' homes or institutions in other parts the city as well as stories about events and people elsewhere.

The visual record from the walking interviews consists, by and large, of shops, parks, places of worship, schools, friends and relatives houses, and other paraphernalia that, at an empirically realist level, could be understood to represent the ongoing relevance of local spaces for the functioning of everyday life. Yet these images represent more than a surface level description of their function. Lee, for example, was keen to show me a communal rubbish store which he duly photographed.

Lee had been living in a hostel, having been made homeless and unemployed. With the help of a support worker, he volunteered with a local charity that offered outreach and training opportunities for disadvantaged young people in the neighbourhood. This included the opportunity to gain experience renovating the communal rubbish stores in between rows of terraced properties in the neighbourhood. During his time with the charity, Lee gained skills in 
basic construction, gardening, and decorating work while renovating the rubbish store. Lee was keen to show me this, declaring that it was 'something I am really proud of'. For Lee, then, the resulting photograph represents the embodied effort that goes into the individual and collective efforts to not only live within, but also actively produce, the neighbourhood I wanted to understand. For others, the images work not to 'show and tell' but also construct particular community narratives. For instance Donna began her walk at the location identified in Figure 3.

\section{[Insert Fig03 here]}

Figure 3. An extraordinary event

Donna explained:

Donna: [This] is where the riots actually started, well they actually started from the middle o' road down here. So I don't know if you want to start from the middle of the road. Are we going to go from where [the place] got its notorious name, do you want to go from here?

\section{Author: Okay.}

Donna: So like from [19]95 from the riots we kind of got labeled this bad area and things changed.

Donna began her walk with a photograph of a piece of waste-ground. The area in the image was the location of a public house that was burnt down during the disturbances. This incident, framed at this point in space and time, was used to structure the rest of Donna's narration of her life in the neighbourhood, of dealing with locational stigma and of efforts to reunite different social groups in the area. Donna's image thus reveals how seemingly mundane images can mask quite 
ANDREW CLARK

extraordinary incidents and histories and the necessity to understand the unobserved interpretations of an image. More importantly, the act of producing the image was a central part of how Donna constructed her community narrative.

Lee's and Donna's images need to be understood as part of a multimodal assemblage; the images demonstrate the degree to which the biographical, temporal, and day-to-day connectedness of life is bound through place. Visual researchers are well-versed in arguments about why images should not be taken at 'face value', but the two cases discussed here go beyond the need for interpretative caution of images produced by others. As I consider below, they also begin to hint at the ways in which the images work towards to producing particular versions of the same phenomenon.

\section{Accounting for Difference: What Does the Visual Contribute?}

It is axiomatic to propose that the data produced from different methods can present different takes on reality. Indeed, advocates of visual approaches often suggest that their methods and techniques can present particularly insightful perspectives. Although I do not want to enter into a debate about 'better' and 'worse' methods, it is worthwhile considering the nature of the knowledge that the two methods introduced here. To do so, I focus on two contradictory cases as a way of starting to understand the contribution an explicitly visual methodology may make.

\section{Case 1: 'Being Local'}

Liz is a student female who moved to the area to complete a degree at a nearby university. Liz's network map revealed an extensive, dense social network that followed a similar presentational style to Rachel's map introduced above. Yet despite the visual complexity of Liz's network, her 
map offered no indication of any ties with more locally situated individuals beyond friends and acquaintances on her study-course at a nearby university. During the participatory mapping technique, Liz attempted to account for the absence of more locally situated ties. When asked about ties to the local area, including, for example, whether she knows her neighbours or frequents local shops she suggested:

Liz: I'd love to walk into the corner shop and say, good morning Bob, how are you?

Author: Mm, why don't you?

Liz: Cos I don't go there often enough. . . . They're always very nice and always say, oh hello, thank you very much and things but I think around, there's so many people around here you feel that you're not, because I live in quite a small community, quite a low population ... everybody knows who you are. . . . I think if I was here for longer I would probably get to know, I'd make more of an effort. Maybe that's the thing. Maybe I'd make more of an effort if I was here for a longer time.

Liz accounted for her limited capacity to establish local networks to her temporary status as a student living in rented accommodation for a fixed period. She also suggests that living in a densely populated urban area, compared with the relative rurality of where she grew up, also plays a part in determining the forms of networks and relationships she constructs. While my analysis offers an alternative interpretation, in so far as the time and resources Liz puts into maintaining her not-so-local ties, together with her part-time job and full-time studies, leave her little time to devote to interactions in her local area, her reasoning has a certain 'common-sense' appeal. Indeed, from this interaction, it is possible to draw parallels with exiting literature around studentification and neighbourhood turn-over (Sage, Smith, \& Hubbard, 2012).

Yet during the walking interview Liz takes us to a particular food store which she photographs (Figure 4) and, seemingly contradicting her previous comments, tells us: 'This is the 
ANDREW CLARK

veg shop [grocery store] . . the men are really nice. If you don't have enough money, they say just pay tomorrow'.

\section{[Insert Fig04 here]}

Figure 4. The vegetable shop

\section{Case 2: Getting By}

The second case involves Claire, a single parent living with three children all under 5. Two of her previous partners are in prison. She does not work and grew up in the area. During the participatory mapping exercise, we discussed the different forms of support Claire draws on to 'get by'. When describing the difficulties she has managing her income, she explains:

Claire: You know it's budgeting what gets you in the nick [prison], because you don't, you have to pay your TV license and you have to pay your water and your gas and then summat [something] changes and then you get a deduction and then summat [something] else happens entirely after that and it just muddles, messes with your head.

Author: Yeah. Does anyone else, do you have to do all that on your own or does anyone help you?

Claire: Yeah erm there's Charlotte that helps me.

Author: Yeah.

Claire: And Leanne. (Long pause) Sure Start.

Claire produced a somewhat fragmented social map with few individuals named on it. She relies on the support of workers at the local Sure Start ${ }^{2}$ office to ensure she pays her bills on time and manages the relatively small income she receives. In doing so, we could theorize about the 
importance of agencies and organizations, including Sure Start. However, her ties are relatively weak, and, during the walking interview, an opportunity arose to discuss other sources of support. In this exchange we catch a glimpse of a more vulnerable set of interactions and relationships, this time with a money lender that Claire draws on to manage financially. While Sure Start offers an official or formalized relationship of support, these work alongside more informal, perhaps less visibly acknowledged and certainly informal interactions:

Claire: They were just walking round knocking on doors.

Author: Okay. Yeah.

Claire: So then I thought, 'Fuck it. I'll get it.' You know what I mean? That's how I got my widescreen TV.

Author: Right. Yeah.

Claire: You know. So that was good for the kids.

Author: Yeah, yeah.

Claire: I mean one time they've [the debt collectors] come back and said, 'Oh you haven't paid a couple, you haven't been paying a couple of payments. You're gonna have to give me 30 quid [pounds]. I'll take your TV away, and then I'll bring it back on Friday'.

Author: Right.

Claire: So I said, 'All right.' I said, 'Bring it back Friday.' I gave him 30 quid, came back, brought the TV back. He said, 'I wasn't even supposed to do that, you know. I was supposed to just take your TV.' I were like, 'Well you can't, you can't take t' TV cos of the kids'.

Attempts to make sense of these two instances of contradiction are caught up in debate about the validity of truth claims and the complexities of triangulation. The search for objective truth, for example, may entail comparing and contrasting data from different perspectives and techniques to gather to test for or validate findings as more, or less, accurate. Others use 
triangulation as a means to compare the same phenomenon from different perspectives or as the interpretivist investigation of multiple insights to an attempt to 'mesh together' insights from different techniques (Moran-Ellis et al., 2006). While there is debate still to be had about how to combine data, practice focuses, by and large, on comparing and contrasting data from across samples so as to assess cross-sample experiences and recognize not only different insights but also the different takes on the realities that different methods can purportedly present. Of course, this is not an innovative revelation and is often the justification, and strength of, mixed and multimethod research. But what is perhaps more fruitful to consider in the cases above is the ways in which the methods we deploy are able to produce, in Liz's case, competing and incompatible and, in Claire's case, additive and complementary insights. In considering how these differences and distinctions emerge, it becomes possible to begin to unravel something of the ways in which working with the visual operates as a form of methodological practice, that is, as a way of doing embodied, sensory experiences as well as being a means of representing the social world.

Accepting that different techniques produce different sorts of data, we are faced with a number of plausible explanations as to how methods 'work' to produce the two cases presented above. First, we can recognize that community is a chaotic concept (Day, 2006; Delanty, 2003) and that as such we are uncovering different dimensions of this complexity through different methods. In this way, perhaps the distinctions in Claire's engagement with our two methods indicate the additive power of combining methods that not just illustrate this complexity but also indicate how it might come into being through the construction of a 'fuller picture' by combining different methods. While it is impossible to account for everything that constitutes community, our different methods can go some way towards trying to achieve this, so the visual can be 
considered an additional tool in the researcher's toolkit, helping to produce a little bit more data and contribute a seemingly even more complete picture. Rachel's eagerness to provide as full or complete a social map as possible may be indicative of a desire to provide a totalizing picture of her community relations.

Second, we could accept, again axiomatically, that people are forgetful, misremember things, or decline to reveal different aspects of their lives to us as researchers. For example, I could reflect on Donna's desire to show me the extraordinary meanings and collective histories of place that are not necessarily observable in the rather mundane landscape she showed us. To see these, we require a participative, post(naïve)realist visual methodology that can grasp the less articulated aspects of community life (Back, 2009). So, we could argue that the visual is somehow better able to reveal that which is seldom talked about; that is, it can reveal a more nuanced understanding of phenomena.

Third, we could offer up both Liz's contradiction and Claire's additive stories as indicative of the value of fieldwork and the opportunities provided for 'being there' to provide serendipitous encounters that make up 'naturally occurring data'. So, the visual properties of the techniques are not what particularly matters; rather it is their embodied experience that allows for greater clarity to be gained through the neighbourhood as a kind of elicitation device.

I want to argue, though, that a fourth process is at work here. Liz's and Claire's different accounts may be the result of the different ontological forms afforded to the communities I am trying to understand. For if community not only means different things to different people, but also different things in different contexts to one individual, then our methodologies may unearth or, more properly, construct these different forms. The performative nature of the techniques described call up different ways in which community discourses (that is as ways of 
ANDREW CLARK

conceptualizing and engaging in the phenomenon as representation of certain social relationships) can operate at a methodological level. For instance, the 'show and tell' of the walking interview may encourage a more romanticized, and certainly localized, representation of community that may encourage participants to actively construct their neighbourhood as a series of practices and engagements with local social phenomena such as neighbours or shops that conflate with normative discourses of localized community. In asking to show me around her neighbourhood, is it possible that, through embarrassment, guilt, or for want of nothing else to present, Liz showed phenomena of what she thought we would expect to be shown, or which she thinks she ought to show to demonstrate her acquaintance with the neighbourhood?

In this sense, the request of participants to 'show me around your neighbourhood' may imply a normative assumption that they have something they are sufficiently familiar with as to demonstrate. It may be this expectation, rather than any subjective practices, that may account for why so many participants' photographs show the paraphernalia of highly localized lives, of community centres, shops, places of worship, and cafes that they did not necessarily frequent. Thus the photographs produced during the walking interviews need to be approached as prompts for further interrogation or elicitation rather as crudely realist attempts to display the neighbourhood. Likewise, the more formalized nature of the social network maps, which force participants to commit relationships to paper and, perhaps, fix a social tie in a way that ensured it must be meaningful in some way, means that some of the more informal, spontaneous, or fleeting relationships, such as those recounted by both Liz and Claire on the walking interviews, were less frequently committed to paper.

This fourth explanation implies that the visual nature of both techniques lies not with issues of method, that is, the collection of empirical observation as data, but rather in its 
methodological effect. It is the nature of how the visual comes into being as a kind of performance or practice of imagining, showing, photographing, or drawing that becomes vital for understanding the phenomena that it purports to represent. It also suggests that visual methodologies are not just processes of representing or depicting phenomena but also methodological performances that come to construct them.

There is a danger in this discussion of prioritizing or preferring one method (and the data produced) over another on the grounds of truthfulness or accuracy. I could, for example, follow others in proclaiming the visual is better able to get at or conjure up a better or clearer representation of real life, and from which it is tempting to slip into a discussion of, at one level, the superiority of method. This is not necessarily problematic given designing research is about making choices, and it is certainly not unusual to read claims that visual methods are somehow better than other techniques for understanding phenomena.

Reflexive engagement with the two techniques described here needs to go beyond issues of the superiority or inferiority of participatory maps and walking interviews over other methods. It should also bring to the fore issues about the subjective and 'real' dimensions of phenomena (in this case, community relations). Participants' images of the neighbourhood are not 'real' depictions of neighbourhood life but rather represent their attempts to perform neighbourhood life for us as outsiders. This is about more than the 'conventional critique' of documentary film making and photography that suggests that 'what has been captured is a rehearsed construction rather than naturally occurring actuality' (Ball \& Smith, 2001, p. 311). The images form part of a normative process of showing, of trying to fix and record for posterity something about the neighbourhood that was worth presenting, as well as preserving, in visual form. 
ANDREW CLARK

While my discussion of the dissonance in Claire's and Liz's data is somewhat speculative, what I see in the workings of both techniques is that the visual depictions are not merely representations of the landscape of community, to be compared and contrasted, or mined for more detailed understanding, but are also indicative of the practices through which geographies, histories, social relationships, and individual experiences intersect in a process of making visual accounts of everyday life. Visual methods need to be seen as mediated acts and should be reflexively critiqued as such. While what we are seeking to understand remains social constructs, and visual methodologies can certainly help us to understand them, we also need to recognize that the constructs we come to see are contingent on the ways in which our participants, and us as researchers, frame our techniques for doing so.

While visually orientated researchers have, by and large, shifted beyond the naive realism that their data somehow represents an objective truth, rather than being constructed as part of the mediation between the researcher and the researched, it is still tempting to treat the visual as somehow more 'real' than other data forms. Perhaps this is why some claim that visual methods can better present the world for how it really is, or are better able to get at those parts of the social world we rarely hear. As my experiences show, while the visual may reveal other forms of insight, these must not be heralded as being better or more real. Rather, they need to be reflexively appreciated for the sort of knowledge they produce.

I am not arguing here for methodological relativity, or even that nothing can be known for certain outside of our methodological constructions. After all, the upshot of this would be an anodyne claim that our methodologies produce different outcomes, or the acceptance of a somewhat crude relativist empiricism to knowledge. Instead, and more helpfully, we can start to think through the ontological status of the visual, as well as the other data we have collected, as 
performative representations. This can then begin to move beyond a methodological relativity to appreciate how the visual is not a mirror image or carbon copy of a precise, objective reality but rather a product of their production. Once we accept this, we can move on to the more important practice of reporting what we have found out from these performances.

However, it is in reporting our findings that we need to remind ourselves again of the contingent nature of the realities we report, for social objects

are real, but they are contingent upon the existence or character of other social objects. They are socially constructed, but real because they cause other things to happen. They are dynamic, yet they may exist over long periods.... [W] hile we socially construct social objects, they may not be reducible to but are contiguous with physical objects and thought objects. (Letherby et al., 2013 p. 159)

Refusing to reduce visual materials to an objective or subjective dualism enables a reengagement with more sympathetic, though no less critical, realist-inspired arguments that imply that socially constructed objects have causal properties. In my case, the socially constructed communities I observe do have implications, both for how participants go on to think about and articulate their communities in the research process but also in the ways in which my reporting of these communities are taken up and worked over by others. Knowledge is used by those with whom I have contact in the field, and others reify their own understandings of community as a direct consequence of what they show us (Emmel \& Clark, 2008). In doing so, the visual data take on real properties as they affect other practices and discourses.

\section{Conclusion}

The two methods discussed here go beyond 'show and tell' or even elicitation techniques to demonstrate how the visual is also performative. Reflexive engagement with the claims we make 
ANDREW CLARK

about our approaches - be they visual or any other - thus needs to consider how realities are made through the deployment of particular techniques. To be clear, I maintain that the visual provides a useful stimulant for accessing some realities, but this does not make it any 'better' or its products 'more real' than those achieved through other methods. Rather, it is a useful lens through which to view the world, but we should always be cautious about the sorts of worlds we come - or think we come - to know. By requesting that people use visual means to depict their lives to us, we are asking them to not just represent, but also perform, construct, and practice the world.

As Law (2009) remarks, 'methods practices are performative. They help to enact the world that they describe' (p. 249). This does not imply a necessarily pessimistic descent into relativism but rather leaves open possibilities for new kinds of realities to emerge. By paying attention to how the visual is done, we can see some of the methodological mechanisms that create the realities we report on. Nor does it mean that visual data are not so completely subjective as to be rendered relativist, for there remain objective outcomes to emerge from them. Rather, it indicates that those working with the visual should remain critically attuned to the types of worlds we think we are coming to see and know.

\section{Acknowledgments}

This paper reports on research funded by the Economic and Social Research Council (Ref 576255017). The Connected Lives project was part of the University of Manchester/University of Leeds Real Life Methods Node of the National Centre for Research Methods. I would especially like to thank Nick Emmel, who was the lead investigator on Connected Lives. 


\section{References}

Amsden J., \& VanWynsberghe, R. (2005). Community mapping as a research tool with youth. Action Research, 3, 357-381. doi:10.1177/1476750305058487

Back, L. (2007). The art of listening. Oxford, England: Berg.

Back, L. (2009). Researching community and its moral projects. 21st Century Society: Journal of the Academy of Social Sciences, 4, 201-214. doi:10.1080/17450140903000316

Ball, M., \& Smith, G. (2001). Technologies of realism? Ethnographic uses of photography and film. In P. Atkinson, A. Coffey, S. Delamont, J. Lofland, \& L. Lofland (Eds.), Handbook of ethnography (pp. 302-320). Thousand Oaks, CA: Sage.

Bergold, J., \& Thomas, S. (2012). Participatory research methods: A methodological approach in motion. Forum: Qualitative Social Research, 13(1), Art. 30.

Cook, T. (2012). Where participatory approaches meet pragmatism in funded (health) research: The challenge of finding meaningful spaces. Forum: Qualitative Social Research, 13(1), Art. 18.

Day, G. (2006). Community and everyday life. Abingdon, England: Routledge.

Delanty, G. (2003). Community. Abingdon, England: Routledge.

Emmel, N. (2008, July). Participatory mapping: An innovative sociological method (Real Life Methods Toolkit No. 3), Manchester, England: University of Manchester.

Emmel, N., \& Clark, A. (2008). User-engagement with community groups: The nature of engagement. Qualitative Researcher, 8, 5-8.

Emmel, N., \& Clark, A. (2009, September). The methods used in connected lives: Investigating networks, neighbourhoods and communities (NCRM Working Paper Series 06/09). Southampton, England: ESRC National Centre for Research Methods: 
ANDREW CLARK

Felstead, A., Jewson, N., \& Walters, S. (2004). Images, interviews and interpretations: Making connections in visual research. In C. J. Pole (Ed.), Seeing is believing? Approaches to visual research (pp. 105-121). Oxford, England: Elsevier.

Fink, J. (2012). Walking the neighbourhood, seeing the small details of community life:

Reflections from a photography walking tour. Critical Social Policy, 32, 31-50. doi:10.1177/0261018311425198

Heath, S., Fuller, A., \& Johnston, B. (2009). Chasing shadows: Defining network boundaries in qualitative social network analysis. Qualitative Research, 9, 645-661.

doi:10.1177/1468794109343631

Hogan, S. (2011). Images of Broomhall, Sheffield: Urban violence, and using the arts as a research aid. Visual Anthropology, 24, 266-280. doi:10.1080/08949468.2010.508996

Holm, G. (2008). Visual research methods: Where are we and where are we going? In S. N. Hesse-Biber \& P. Leavy (Eds.), Handbook of emergent methods (pp. 325-342). New York, NY: Guilford Press.

Knoke, D., \& Yang, S. (2008). Social network analysis (2nd ed.). Thousand Oaks, CA: Sage.

Law, J. (2009). Seeing like a survey. Cultural Sociology, 3, 239-256.

doi:10.1177/1749975509105533

Letherby, G., Scott, J. P., \& Williams, M. (2013). Objectivity and subjectivity in social research. London, England: Sage.

Moran-Ellis, J., Alexander, V. D., Cronin, A., Dickinson, M., Fielding, J., Sleney, J. \& Thomas, H. (2006). Triangulation and integration: Processes, claims and implications. Qualitative Research, 6, 45-59. doi:10.1177/1468794106058870 
Pain, H. (2012). A literature review to evaluate the choice and use of visual methods. International Journal of Qualitative Methodology, 11, 303-319.

Pauwels, L. (2012). Contemplating the state of visual research: An assessment of obstacles and opportunities. In S. Pink (Ed.), Advances in visual methodology (pp. 248-264). London, England: Sage.

Pink, S. (Ed.). (2012). Advances in visual methodology. London, England: Sage.

Prosser, J. (2011). Visual methodology: Toward a more seeing research. In N. K. Denzin \& Y. S. Lincoln (Eds.), The Sage handbook of qualitative research (4th ed., pp. 479-495). Thousand Oaks, CA: Sage.

Sage, J., Smith, D., \& Hubbard, P. (2012). The diverse geographies of studentification: Living alongside people not like us. Housing Studies, 27, 1057-1078.

doi:10.1080/02673037.2012.728570

Sweetman, P. (2009). Revealing habitus, illuminating practice: Bourdieu, photography and visual methods. The Sociological Review, 57, 491-511. doi:10.1111/j.1467954X.2009.01851.x

Wiles, R., Bengry-Howell, A., Crow, G., \& Nind, M. (2013). But is it innovation? The development of novel methodological approaches in qualitative research. Methodological Innovations, 8(1), 18-33. doi:10.4256/mio.2013.002

\begin{abstract}
About the Author
Andrew Clark is reader in sociology at the University of Salford. His research explores the relationships between marginalization and the spatiality of social life, particularly in relation to
\end{abstract}


well-being and community. He is interested in methodological innovation and is undertaking research on dementia, neighbourhoods, and everyday life.

\section{Notes}

${ }^{1}$ This and all other names in this paper are pseudonyms.

${ }^{2}$ Sure Start was a UK government-led initiative that offers a range of services focusing on family health, early years care, education, and well-being programmes to children aged 4 and under.

\section{Figure 01}

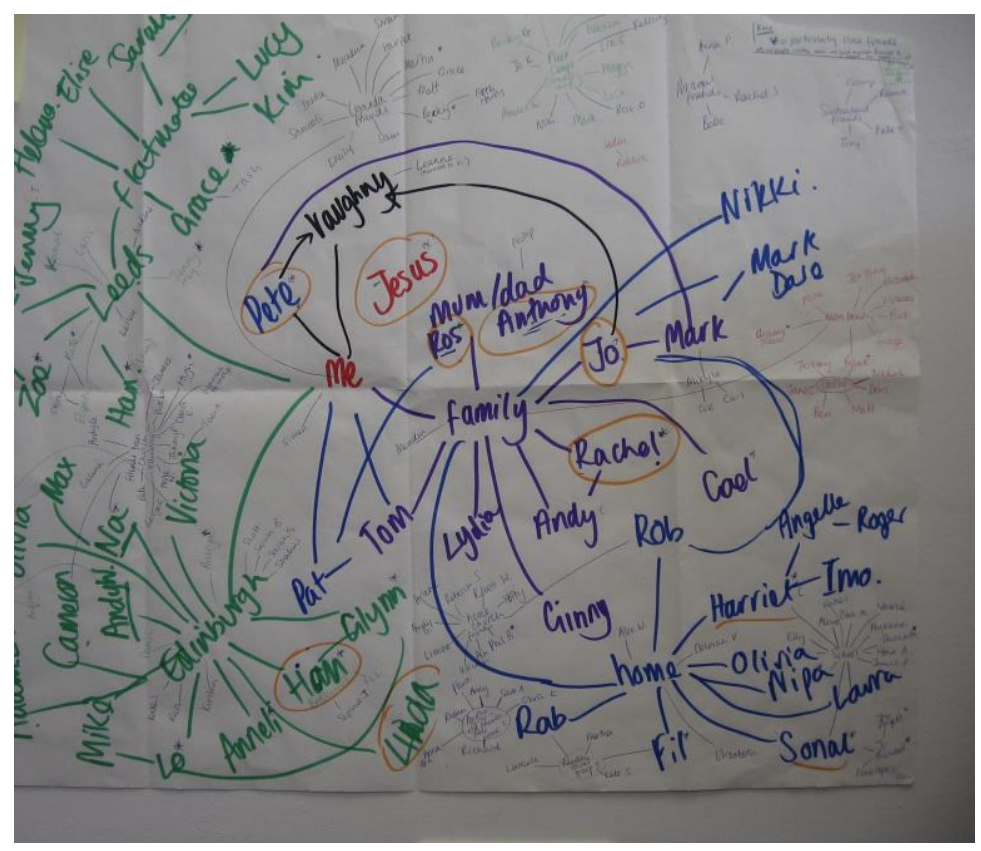

Figure 02 


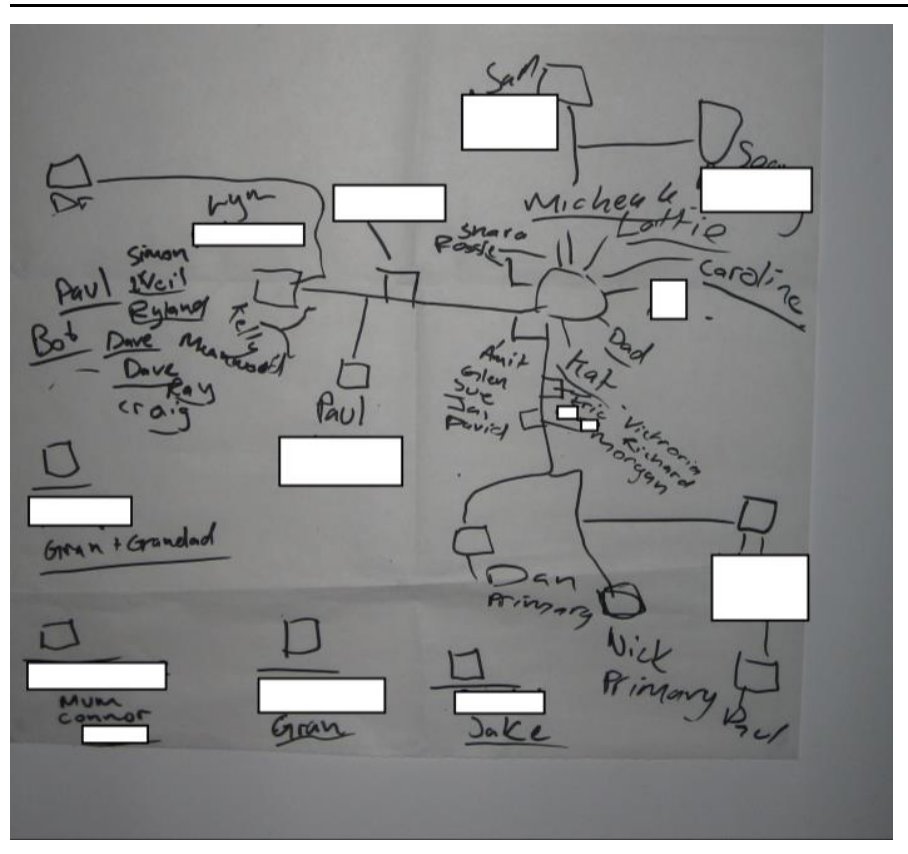

Figure 03

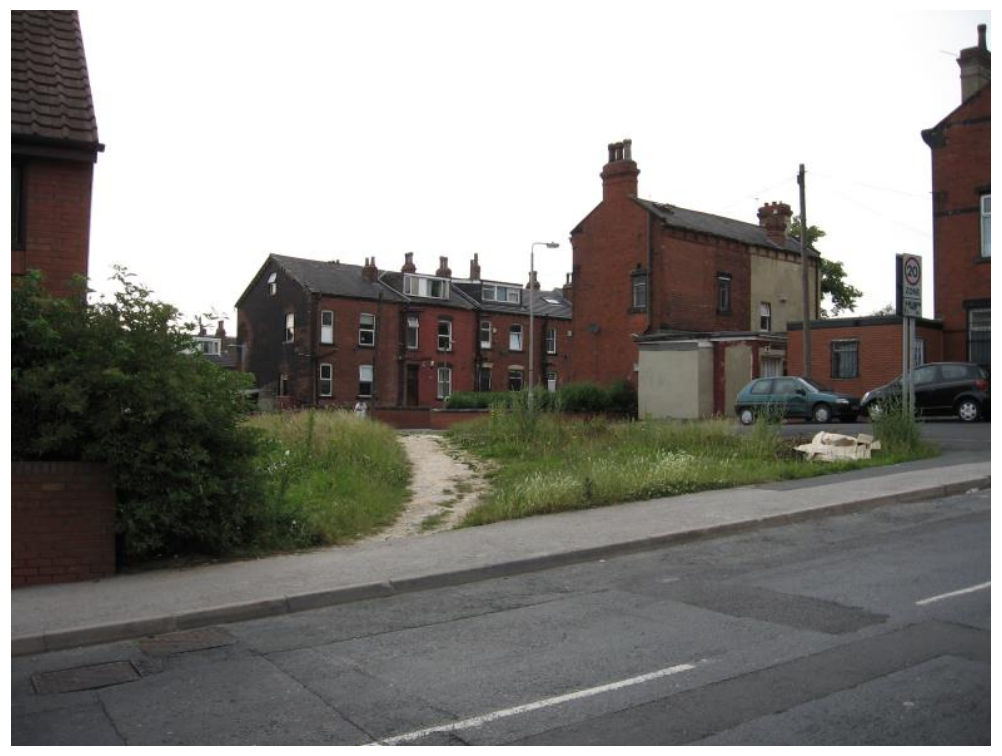

Figure 04 
ANDREW CLARK

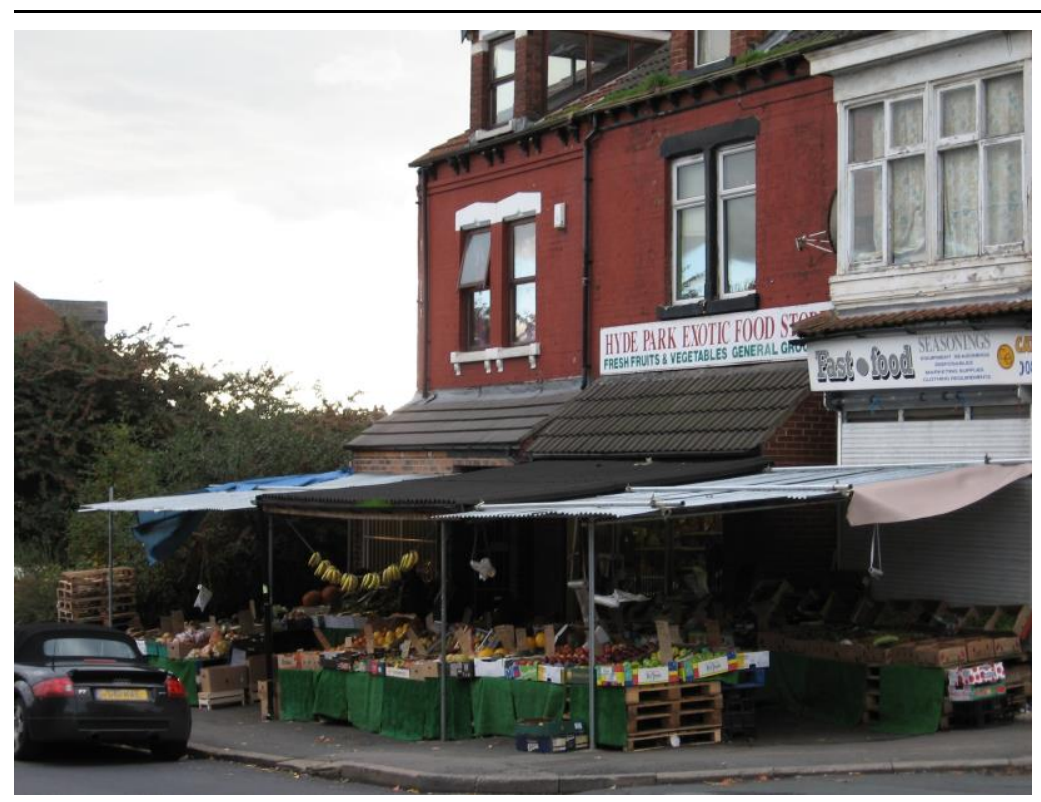

